
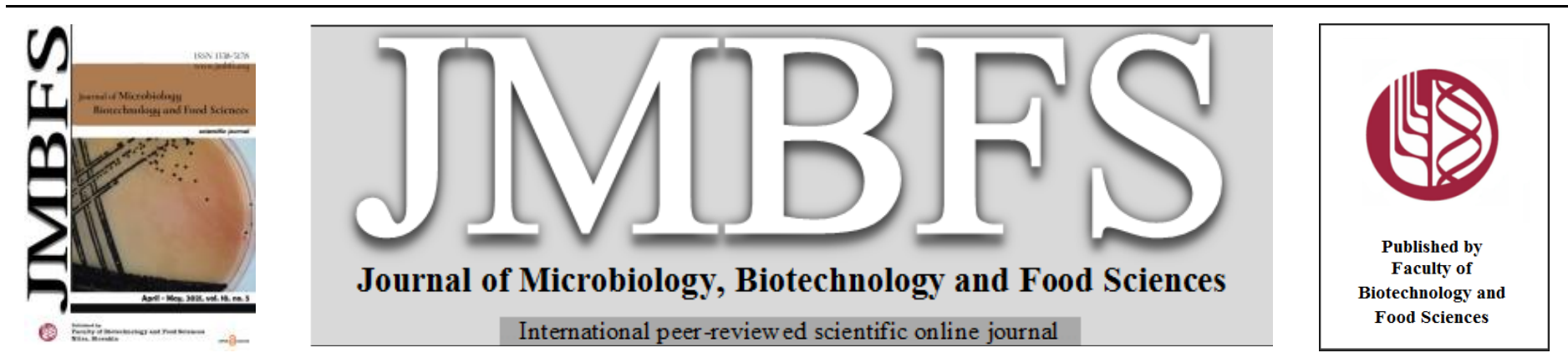

\title{
DRYING KINETICS, FOURIER-TRANSFORM INFRARED SPECTROSCOPY ANALYSIS AND SENSORY EVALUATION OF SUN, HOT-AIR, MICROWAVE AND FREEZE DRIED MANGO LEATHER
}

\author{
Tanmay Sarkar, ${ }^{1,2}$, Suman Kumar Saha ${ }^{l}$ Molla Salauddin ${ }^{l}$, Runu Chakraborty $^{l}$ * \\ Address(es): \\ ${ }^{1}$ Jadavpur University, Faculty of Engineering and Technology, Department of Food Technology and Biochemical Engineering, 188, Raja S.C. Mallick Road, Jadavpur, \\ Kolkata- 700032, West Bengal, India. \\ ${ }^{2}$ Malda Polytechnic, West Bengal State Council of Technical Education, Govt. of West Bengal, India.
}

*Corresponding author: crunu@ hotmail.com

https://doi.org/10.15414/jmbfs.3313

\section{ARTICLE INFO}

Received 21. 6. 2020

Revised 23. 11. 2020

Accepted 23. 11. 2020

Published 1. 4. 2021

Regular article

open $\partial_{\text {ACCESS }}$

\begin{abstract}
Mango leather produced from dried mango pulp is a traditional fruit product in India. Traditionally it is processed through natural convective drying or sun drying of ripe mango pulp. Mango leather was produced through sun, convective (hot air), freeze, and microwave drying. Drying kinetics was studied with the help of nine empirical models used extensively in food industries. Root mean square error (RMSE), correlation coefficient $\left(\mathrm{R}^{2}\right)$, and the sum of square errors (SSE) these four statistical measures were examined for nine different models to learn the best-fitted model. The Fourier-transform infrared spectroscopy study was conducted for compositional analysis of differently dried samples in the wavelength range of $400-4000 \mathrm{~cm}^{-1}$ at ambient temperature. For sensory analysis, the test panel was constructed as per ISO 8586-1. ISO 4120:2004, ISO 5496:2005, ISO 10399:2004 standards were maintained for selecting panel members. Quantitative descriptive analysis of different mango leather was estimated as per the protocols defined in ISO 11035:1994.
\end{abstract}

Keywords: Snack food, Model fitting, Food analysis, Quantitative descriptive analysis

\section{INTRODUCTION}

Mango leather is cherished as a snack food in India, for its consummate organoleptic properties (Sarkar et al., 2018). Being a tropical country, sun drying is a widely practiced method for mango leather preparation, though it is a climate-dependent process. Due to uniform drying characteristics, hot air oven drying is adopted by different food industries (Fernando et al., 2016). Freeze drying is not generally employed to produce mango leather, however, it is assumed as a superior method to maintain the nutritional quality of the product (Acar et al., 2014). Being a rapid and controllable process microwave drying is considered as an energy-saving method as well as cost-effective (Zarein $\boldsymbol{e t}$ al., 2013). To design mango leather processing for industrial applications, mathematical modeling is indispensable. Several studies have been available for drying kinetics of mango slices dried under tunnel dryer (Goyal et al., 2006), convective dryer (Dissa et al., 2014), Osmo-dehydrated mango (Kumar et al., 2014), solar drying (Dissa et al., 2009), though an inadequate number of studies have been found for drying kinetics of mango leather processing concluded by drying of mango pulp in different drying techniques. It is the first approach to study the sun drying (traditional approach) and freeze drying kinetics of mango leather processing.

Fourier-transform infrared spectroscopy (FTIR) progressively gains popularity in the field of food analysis due to its fast and non-destructive fingerprint modus operandi (Erwanto et al., 2016, Ojha et al., 2018). Few research works have been reported for FTIR analysis of mango. Duarte $\boldsymbol{e t}$ al., 2002 estimated sugar content of mango juice in different stages of ripening, Jha et al., 2010 quantified the sugar content of commercially available mango juice on market, Olale $\boldsymbol{e t}$ al., 2017 also determined sugar content of two mango varieties of Kenya, Leizi $\boldsymbol{e t ~ a l . ,}$ 2017 predicted maturity stage of mango by FTIR analysis. Though as per our knowledge, it is the first approach to study the FTIR spectrum for differently dried mango.
Sensory perception of consumer and product characteristics like colour, texture, and flavour profile can be correlated with quantitative descriptive analysis (QDA) of concerned food material. Though various studies are available in the field of sensory science (Lestringant et al., 2019), inadequate results are there in the zone of QDA study for ethnic food like mango leather, as per our literature survey this is the first QDA study for mango leather

The aim of this study is to determine the drying kinetics for mango leather processing under sun, hot, microwave and freeze drying; FTIR spectroscopic characteristics of different mango leathers and QDA sensory estimation of the final product.

\section{MATERIALS AND METHODS}

Sun drying $\left(30 \pm 5{ }^{\circ} \mathrm{C}\right)$, hot air oven $\left(70{ }^{\circ} \mathrm{C}\right)$ (Concepts International, Kolkata, India), microwave (200 W) (Samsung, Combi CE1031LAT, Mumbai, India) and freeze drying $\left(-40{ }^{\circ} \mathrm{C}, 0.1 \mathrm{mBar}\right.$ pressure) (FDU 1200, EYELA, Japan) was adapted as described in Sarkar et al., 2020. Puree load was $0.5 \mathrm{~g} / \mathrm{cm}^{2}$. The total soluble solid of the pulp was maintained at $25^{\circ} \mathrm{B}$ with addition of sugar.

In order to describe the most effective model for mango leather (Langra variety) processing thin layer drying models of various types were taken into consideration (Table 1). In calculating the Moisture Ratio (MR) during drying of mango pulp an equation stated below is used-

$M R=\frac{M-M_{e q}}{M_{i n}-M_{e q}}$

Where, $\mathrm{M}=$ moisture content of mango leather at a different time interval $(\mathrm{t})(\mathrm{kg}$ moisture/kg dry leather), $\mathrm{M}_{\mathrm{in}}=$ moisture present in mango pulp initially $(\mathrm{kg}$ moisture/kg dry leather), $\mathrm{M}_{\mathrm{eq}}=$ moisture in mango leather at equilibrium $(\mathrm{kg}$ moisture/kg dry leather) (Arslan et al., 2010). In determining the best fitting model parameters like Root Mean Square Error (RMSE), Correlation Coefficient $\left(\mathrm{R}^{2}\right)$, and Sum of Square Errors (SSE) have been taken into account. 
$\mathrm{R}^{2}=1-\frac{\sum\left(M R_{p}-M R_{e}\right)^{2}}{\sum_{i=1}^{N}\left(M R_{m}-M R_{e}\right)^{2}}$

$\mathrm{RMSE}=\sqrt{\left[\frac{1}{N} \sum_{i=1}^{N}\left(M R_{e}-M R_{p}\right)^{2}\right]}$

$\mathrm{SS}_{\mathrm{e}}=\sum\left(M R_{t}-M R_{m}\right)^{2}$

Where, $\mathrm{MR}_{\mathrm{e}}-\mathrm{MR}$ from experiments, $\mathrm{MR}_{\mathrm{p}}$ - model predicted $\mathrm{MR}, \mathrm{N}$ - observation number, $\mathrm{MR}_{\mathrm{t}^{-}}$moisture ratio at time $\mathrm{t}, \mathrm{MR}_{\mathrm{m}}$ - mean moisture ratio (Acar et al., 2014). Fick's law of diffusion defines the drying behaviour of food material during falling rate period. Throughout the process it was assumed that effective moisture diffusivity and temperature remained constant, hence shrinkage was negligible and change in moisture content was only due to diffusion, the equation for unsteady-state moisture diffusion of an infinite slab (Demiray et al., 2017) can be represented as follows-

$\mathrm{MR}=\frac{8}{\pi^{2}} \sum_{n=1}^{\infty} \frac{1}{(2 Z-1)^{2}} e^{\left[-\frac{\left.(2 Z-1)^{2} \pi^{2} D_{e} t\right)}{4 L^{2}}\right]}$

Where $D_{e}$ - effective moisture diffusivity $\left(\mathrm{m}^{2} / \mathrm{s}\right)$ and $\mathrm{L}-($ sample thickness $) / 2$ (3mm).
The logarithmic form of the first portion of the equation (5) can be expressed as:

$\ln (\mathrm{MR})=\ln \frac{8}{\pi^{2}}-\left(\frac{\pi^{2} D_{e} t}{4 L^{2}}\right)$

$D_{e}$ was estimated from $\ln (\mathrm{MR})$ versus t plot, considering the following equation:

$\mathrm{D}_{\mathrm{e}}=-\frac{\text { Slope } 4 L^{2}}{\pi^{2}}$

Bruker Fourier-transform infrared spectroscopy (FTIR) spectrophotometer (Bruker Tensor 27, Bruker Corp, Massachusetts, USA) was used in recording the FTIR spectra in duplicate at a temperature of $25^{\circ} \mathrm{C}$, the wavelength range was $400-4000 \mathrm{~cm}^{-1}$ and sixteen scans were taken at $2 \mathrm{~cm}^{-1}$ resolution. Analysis of spectral data was carried out with the help of BRUKER software version 7.5 (1991) (Origin Lab Corporation, Northampton, MA, USA).

Four male and same number of female participants in the age bracket of 25-40 years were considered to construct the panel, as per ISO 8586-1 (1993) for sensory analysis. ISO 4120:2004 was the standard considered for triangular discrimination; ISO 5496:2005 was the standard for odour and taste identification proficiencies. ISO 10399:2004 was the standard used for ability of discrimination between two food materials with respect to sensory qualities. The sensory attributes of mango leather prepared under traditional (SD) and contemporary (HAD, MWD, and FD) dehydration techniques was estimated according to ISO 11035:1994. The evaluations of panelists and panel have been carried out through Panel Check software (Norwegian Food Research Institute and the Technical University of Denmark) version V1.4.2.

Table 1 The drying models considered for freeze dried, hot air dried, microwave dried and microwave convective dried mango leather processing.

\begin{tabular}{llll}
\hline SI No. & Name of Model & Equation & Reference \\
\hline $\mathbf{1}$ & Page & $\mathrm{MR}=e^{-k t^{n}}$ & (Page et al., 1949) \\
\hline $\mathbf{2}$ & Modified Page & $\mathrm{MR}=e^{(-k t)^{n}}$ & (White et al., 1981) \\
\hline $\mathbf{3}$ & Logarithmic & $\mathrm{MR}=a e^{-k t^{n}+\mathrm{c}}$ & (Yaldiz et al., 2001) \\
\hline $\mathbf{4}$ & Lewis & $\mathrm{MR}=e^{-k t}$ & (Lewis et al., 1921) \\
\hline $\mathbf{5}$ & Henderson & $\mathrm{MR}=a e^{-k t}$ & (Henderson et al., 1961) \\
\hline $\mathbf{6}$ & Two term exponential & $\mathrm{MR}=a e^{-k t}+(1-a) e^{-k b t}$ & (Yaldiz et al., 2001) \\
\hline $\mathbf{7}$ & Wang and Singh & $\mathrm{MR}=1+a t+b t^{2}$ & (Wang et al., 1978) \\
\hline $\mathbf{8}$ & Fernando and Amarasinghe & $\mathrm{MR}=\left(1+a t+b t^{2}\right) /(1+c t)$ & (Fernando et al., 2016) \\
\hline $\mathbf{9}$ & Midilli & $\mathrm{MR}=a e^{-k t^{n}+b t}$ & (Midilli et al., 2018) \\
\hline
\end{tabular}

Table 2 The model parameters for freeze dried, hot air dried, microwave dried and microwave convective dried mango leather with statistical measures of each model

\begin{tabular}{|c|c|c|c|c|c|}
\hline Process & Model & Model Coefficients & $\mathbf{R}^{2}$ & RMSE & $\mathbf{S S}_{\mathbf{e}}$ \\
\hline \multirow{9}{*}{ Sun drying } & {$[1]\left[\mathrm{MR}=e^{-k t^{n}}\right]$} & $\begin{array}{l}\mathrm{k}=0.000309 \\
\mathrm{n}=\mathbf{1 . 1 6 4 7}\end{array}$ & 0.996842 & 0.035846 & 0.03983 \\
\hline & {$[2]\left[\mathrm{MR}=e^{(-k t)^{n}}\right]$} & $\begin{array}{l}\mathrm{k}=\mathbf{0 . 0 0 0 9 6 4} \\
\mathrm{n}=\mathbf{1 . 0 0 0 0}\end{array}$ & 0.996873 & 0.015390 & 0.00734 \\
\hline & {$[3]\left[\mathrm{MR}=a e^{-k t^{n}}+\mathrm{c}\right]$} & $\begin{array}{l}a=1.1481 \\
k=0.000817 \\
c=-0.1202\end{array}$ & 0.998147 & 0.011847 & 0.00435 \\
\hline & {$[4]\left[\mathrm{MR}=e^{-k t}\right]$} & $k=0.000964$ & 0.996873 & 0.015390 & 0.00734 \\
\hline & {$[5]\left[\mathrm{MR}=a e^{-k t}\right]$} & $\begin{array}{l}\mathrm{a}=\mathbf{1 . 0 5 1 0} \\
\mathrm{k}=\mathbf{0 . 0 0 1 0 2}\end{array}$ & 0.995685 & 0.018077 & 0.01013 \\
\hline & {$[6]\left[\mathrm{MR}=a e^{-k t}+(1-a) e^{-k b t}\right]$} & $\begin{array}{l}\mathbf{a}=\mathbf{1 . 5 2 9 2} \\
\mathbf{k}=\mathbf{0 . 0 0 0 7 3 9} \\
\mathbf{b}=\mathbf{0 . 5 9 5 1}\end{array}$ & 0.998220 & 0.011611 & 0.00418 \\
\hline & {$[7]\left[\mathrm{MR}=1+a t+b t^{2}\right]$} & $\begin{array}{l}a=-0.00079 \\
b=1.79 \times 10^{-7}\end{array}$ & 0.999258 & 0.007495 & 0.00174 \\
\hline & {$[8]\left[\mathrm{MR}=\left(1+a t+b t^{2}\right) /(1+c t)\right]$} & $\begin{array}{l}a=-0.00089 \\
b=2.201 \times 10^{-7} \\
c=-0.00013\end{array}$ & 0.999331 & 0.007118 & 0.00157 \\
\hline & {$[9]\left[\mathrm{MR}=a e^{-k t^{n}}+b t\right]$} & $\begin{array}{l}\mathbf{a}=\mathbf{0 . 9 9 7 6} \\
\mathbf{k}=\mathbf{0 . 0 0 0 2 6 0} \\
\mathbf{n}=\mathbf{1 . 1 9 3 8} \\
\mathbf{b}=\mathbf{8 . 7 1 1 \times 1 0 ^ { - 6 }}\end{array}$ & 0.999479 & 0.006283 & 0.00122 \\
\hline \multirow{5}{*}{ Hot air drying } & {$[1]\left[\mathrm{MR}=e^{-k t^{n}}\right]$} & $\begin{array}{l}\mathbf{k}=\mathbf{0 . 0 0 3 7 1} \\
\mathbf{n}=\mathbf{1 . 0 0 8 1}\end{array}$ & 0.996745 & 0.016077 & 0.00491 \\
\hline & {$[2]\left[\mathrm{MR}=e^{(-k t)^{n}}\right]$} & $\begin{array}{l}\mathbf{k}=\mathbf{0 . 0 0 3 8 9} \\
\mathbf{n}=\mathbf{1 . 0 0 0}\end{array}$ & 0.996742 & 0.016083 & 0.00491 \\
\hline & {$[3]\left[\mathrm{MR}=a e^{-k t^{n}}+\mathrm{c}\right]$} & $\begin{array}{l}\mathbf{a}=\mathbf{0 . 9 8 5 3} \\
\mathrm{k}=\mathbf{0 . 0 0 4 3 5} \\
\mathrm{c}=\mathbf{0 . 0 3 9 1}\end{array}$ & 0.997843 & 0.013088 & 0.00325 \\
\hline & [4] $\left[\mathrm{MR}=e^{-k t}\right]$ & $k=0.00389$ & 0.996742 & 0.016083 & 0.00491 \\
\hline & {$[5]\left[\mathrm{MR}=a e^{-k t}\right]$} & $\begin{array}{l}a=1.0113 \\
k=0.00394\end{array}$ & 0.996966 & 0.015520 & 0.00458 \\
\hline
\end{tabular}




\begin{tabular}{|c|c|c|c|c|c|}
\hline & {$[6]\left[\mathrm{MR}=a e^{-k t}+(1-a) e^{-k b t}\right]$} & $\begin{array}{l}a=0.2882 \\
k=0.00412 \\
b=0.8967\end{array}$ & 0.996383 & 0.016946 & 0.00546 \\
\hline & {$[7]\left[\mathrm{MR}=1+a t+b t^{2}\right]$} & $\begin{array}{l}a=0.00329 \\
b=3.135 \times 10^{-6}\end{array}$ & 0.997379 & 0.014426 & 0.00395 \\
\hline & {$[8]\left[\mathrm{MR}=\left(1+a t+b t^{2}\right) /(1+c t)\right]$} & $\begin{array}{l}a=-0.00287 \\
b=2.558 \times 10^{-6} \\
c=0.000765\end{array}$ & 0.999075 & 0.008568 & 0.00139 \\
\hline & {$[9]\left[\mathrm{MR}=a e^{-k t^{n}}+b t\right]$} & $\begin{array}{l}\mathbf{a}=\mathbf{0 . 9 9 6 7} \\
\mathrm{k}=\mathbf{0 . 0 0 1 9 1} \\
\mathbf{n}=\mathbf{1 . 1 5 1 1} \\
\mathbf{b}=\mathbf{0 . 0 0 0 1 3 2}\end{array}$ & 0.999567 & 0.005867 & 0.0006539 \\
\hline \multirow{9}{*}{ Microwave drying } & {$[1]\left[\mathrm{MR}=e^{-k t^{n}}\right]$} & $\begin{array}{l}\mathbf{k}=\mathbf{0 . 0 2 3 7} \\
\mathbf{n}=\mathbf{0 . 9 9 7 7}\end{array}$ & 0.999987 & 0.001031 & 0.0000159 \\
\hline & {$[2]\left[\mathrm{MR}=e^{(-k t)^{n}}\right]$} & $\begin{array}{l}\mathbf{k}=\mathbf{0 . 0 2 3 5} \\
\mathrm{n}=\mathbf{1 . 0 0 0}\end{array}$ & 0.999986 & 0.001054 & 0.0000167 \\
\hline & {$[3]\left[\mathrm{MR}=a e^{-k t^{n}}+\mathrm{c}\right]$} & $\begin{array}{l}\mathbf{a}=\mathbf{0 . 9 9 7 1} \\
\mathbf{k}=\mathbf{0 . 0 2 3 7} \\
\mathbf{c}=\mathbf{0 . 0 0 3 4}\end{array}$ & 0.999991 & 0.000879 & 0.0000116 \\
\hline & [4] $\left[\mathrm{MR}=e^{-k t}\right]$ & $\mathrm{k}=\mathbf{0 . 0 2 3 5}$ & 0.999986 & 0.001054 & 0.0000167 \\
\hline & {$[5]\left[\mathrm{MR}=a e^{-k t}\right]$} & $\begin{array}{l}a=0.9996 \\
k=0.0235\end{array}$ & 0.999986 & 0.001076 & 0.0000174 \\
\hline & {$[6]\left[\mathrm{MR}=a e^{-k t}+(1-a) e^{-k b t}\right]$} & $\begin{array}{l}\mathbf{a}=\mathbf{0 . 1 3 9 6} \\
\mathbf{k}=\mathbf{0 . 0 2 0 2} \\
\mathbf{b}=\mathbf{1 . 1 9 5 1}\end{array}$ & 0.999988 & 0.000978 & 0.0000143 \\
\hline & {$[7]\left[\mathrm{MR}=1+a t+b t^{2}\right]$} & $\begin{array}{l}a=-0.0131 \\
b=0.00011\end{array}$ & 0.996587 & 0.016679 & 0.00417 \\
\hline & {$[8]\left[\mathrm{MR}=\left(1+a t+b t^{2}\right) /(1+c t)\right]$} & $\begin{array}{l}a=-0.0131 \\
b=0.000052 \\
c=0.0107\end{array}$ & 0.999994 & 0.00071 & 0.0000008 \\
\hline & {$[9]\left[\mathrm{MR}=a e^{-k t^{n}}+b t\right]$} & $\begin{array}{l}\mathbf{a}=\mathbf{0 . 9 9 7} \\
\mathbf{k}=\mathbf{0 . 0 2 3 3} \\
\mathbf{n}=\mathbf{1 . 0 0 4 5} \\
\mathbf{b}=\mathbf{0 . 0 0 0 0 4 5}\end{array}$ & 0.999998 & 0.000425 & 0.000003 \\
\hline \multirow{9}{*}{ Freeze Drying } & {$[1]\left[\mathrm{MR}=e^{-k t^{n}}\right]$} & $\begin{array}{l}k=0.00044 \\
n=1.208\end{array}$ & 0.992878 & 0.02535 & 0.0135 \\
\hline & {$[2]\left[\mathrm{MR}=e^{(-k t)^{n}}\right]$} & $\begin{array}{l}k=0.00168 \\
n=1.0000\end{array}$ & 0.988043 & 0.032846 & 0.02266 \\
\hline & {$[3]\left[\mathrm{MR}=a e^{-k t^{n}}+\mathrm{c}\right]$} & $\begin{array}{l}a=1.0962 \\
k=0.00163 \\
c=-0.0438\end{array}$ & 0.988103 & 0.032705 & 0.02254 \\
\hline & [4] $\left[\mathrm{MR}=e^{-k t}\right]$ & $\mathrm{k}=0.00168$ & 0.988043 & 0.032846 & 0.02266 \\
\hline & {$[5]\left[\mathrm{MR}=a e^{-k t}\right]$} & $\begin{array}{l}a=1.064 \\
k=0.00179\end{array}$ & 0.987369 & 0.03376 & 0.02393 \\
\hline & {$[6]\left[\mathrm{MR}=a e^{-k t}+(1-a) e^{-k b t}\right]$} & $\begin{array}{l}a=1.2756 \\
k=0.00128 \\
b=0.3725\end{array}$ & 0.986915 & 0.034362 & 0.0248 \\
\hline & {$[7]\left[\mathrm{MR}=1+a t+b t^{2}\right]$} & $\begin{array}{l}a=-0.00139 \\
b=5.485 \times 10^{-7}\end{array}$ & 0.995677 & 0.019751 & 0.00819 \\
\hline & {$[8]\left[\mathrm{MR}=\left(1+a t+b t^{2}\right) /(1+c t)\right]$} & $\begin{array}{l}a=-0.00156 \\
b=6.647 \times 10^{-7} \\
c=-0.0003\end{array}$ & 0.997105 & 0.016163 & 0.00549 \\
\hline & {$[9]\left[\mathrm{MR}=a e^{-k t^{n}}+b t\right]$} & $\begin{array}{l}\mathbf{a}=\mathbf{0 . 9 7 3 6} \\
\mathbf{k}=\mathbf{0 . 0 0 0 0 7 6} \\
\mathbf{n}=\mathbf{1 . 5 0 9 5} \\
\mathbf{b}=\mathbf{0 . 0 0 0 0 8 2}\end{array}$ & 0.99877 & 0.010534 & 0.00233 \\
\hline
\end{tabular}

\section{RESULTS AND DISCUSSION}

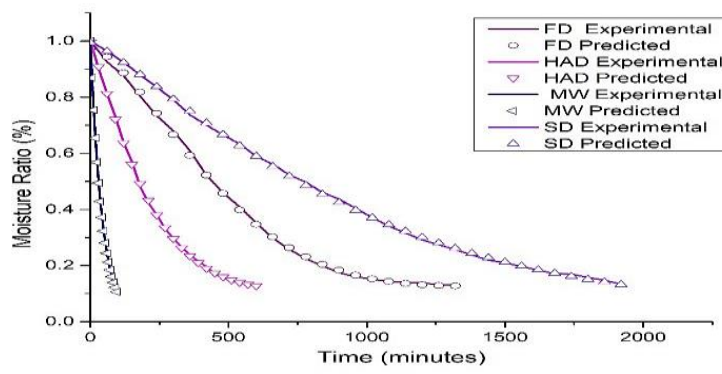

Figure 1 Drying kinetics of freeze dried, hot air dried, microwave dried and microwave convective dried mango leather
Considering the thin layer drying models and assuming an even distribution of temperature and moisture within mango pulp during the different drying processes, the endured parameters were modeled and thereafter fitted to all the nine equations (Table 1). Model convolutions can be ascribed by the constants considered for each model, though the best-fitted model is described by various statistical measures and not by the constants that exist within the model (Onwude et al., 2016). The experimental results fitted well with the entire models (Table 2). It was observed that the Midilli model (Midilli et al., 2002) fitted best with the $\mathrm{R}^{2}$ of $0.999479,0.999567,0.999998,0.99877$ along with lowest RMSE and SSE value of $0.006283,0.005867,0.000425,0.010534$ and $0.00122,0.0006539$, $0.000003,0.00233$ for sun, hot air, microwave and freeze drying respectively. The plots for drying kinetics of all the four drying processes predicted best by the Midilli model are presented in Fig. 1. Midilli model predicted sun drying better for Bitter leaves, Crain-crain leaves and the fever leaves drying (Alara et al., 2018 ; Philip et al., 2007), hot air drying better for broccoli stalk, mushroom slice drying (Salim et al., 2017 ; Dinani et al., 2014) , microwave drying better for apple slice and onion slice drying (Sufer $\boldsymbol{e t}$ al., 2017), freeze drying better for Kiwi slice and kefir drying (Izli et al., 2016 ; Isleroglu et al., 2019) in prior studies. 
From initial moisture content of $5.45 \mathrm{~kg}$ moisture $/ \mathrm{kg}$ dry leather to attain the final moisture content of $0.163 \mathrm{~kg}$ moisture $/ \mathrm{kg}$ dry leather, irrespective of drying methods used moisture amputation of mango pulp was transpired mainly in the falling rate period and the constant rate period was not observed for any of the drying methods. During the thin layer drying of mango pulp, the temperature distribution was assumed to be uniform, as the thickness of the layer was uniform (Onwude et al., 2016). In the initial phase of drying due to the fast diffusion of water molecules the rate of drying was fast as cell wall pathway and transmembrane transport way define the moisture movement in this phase, while the moisture vapour diffusion became dominant in the later phase of drying through the symplastic transport mechanism, which ensued in a slowdown in the drying rate. Effective moisture diffusivity $\left(D_{e}\right)$ is the key parameter to describe the falling rate period. The range for $D_{e}$ gained from $26.37 \times 10^{-7} \mathrm{~m}^{2} / \mathrm{s}$ (sun drying) to $2363 \times 10^{-7} \mathrm{~m}^{2} / \mathrm{s}$ for microwave drying. Whereas, intermediate $D_{e}$ value of $193.7 \times 10^{-7} \mathrm{~m}^{2} / \mathrm{s}$ and $44.63 \times 10^{-7} \mathrm{~m}^{2} / \mathrm{s}$ were observed for convective drying (hot air oven) and freeze drying respectively. These large deviations in diffusivities during different modes of drying procedures can be explicated by considering the diversified approach of energy transmission to the mango pulp. Similar results were reported for germinated corn by Bualuang $\boldsymbol{e t}$ al., 2017 and for grape by Maskan et al., 2002. The amount of moisture present within the mango pulp responsible chiefly for its dielectric characteristics. The electromotive energy absorbs by the polar components of mango pulp, mainly the water molecules, fasten the rate of evaporation, therefore the absorption of electromotive energy absorption is directly proportional to leftover moisture. In contrast to the sun and hot drying, microwave can infiltrate the outermost inert dry layer and produce an outward flux of vapour from the inner side of the mango leather (Wang et al. 2007). An extended falling rate was observed for SD. Similar result was observed for sun drying of tomato slices by Rajkumar et al., 2007. Due to the sluggish rate of heat transfer, sun drying was the leisureliest drying process with drying time 32 hours followed by freeze drying with a drying time of 22 hours and hot air drying with drying time of 10 hours, where convective heat transfer was responsible for moisture removal. During freeze drying, due to sublimation, moisture reaches to surface of mango leather through the capillary action. As the partial vapour pressure of mango pulp was higher than that of lyophilizer condenser, the moisture at the surface front got dried out (Acar et al., 2014).

\section{FOURIER-TRANSFORM INFRARED SPECTROSCOPY ANALYSIS (FTIR)}

Each spectrum containing more or less fifteen to sixteen peaks of ranges lies in between 448-3557 $\mathrm{cm}^{-1}$ (Fig. 2). Carboxylic groups (-COO) of pectin shows symmetric stretching at peak value $1336 \mathrm{~cm}^{-1}$ (SD).On the other hand, two bands appearing at $1422-1425 \mathrm{~cm}^{-1}$ (SD, HAD, MWD, FD) and 1638-1642 $\mathrm{cm}^{-1}$ (HAD SD, MWD) (Ajila et al., 2010) represent the asymmetric and symmetric stretching frequency of ionic carboxylic group. Conjugation of the carbonyl group $(\mathrm{C}=0)$ with $\mathrm{C}=\mathrm{C}$ and $\mathrm{C}=\mathrm{O}$ stretch can be represented by the peaks appear close to $1638 \mathrm{~cm}^{-1}$. In the case of primary and secondary amides, the amide $(\mathrm{N}-$ $\mathrm{H}$ ) bending may be related to the peak at $1642 \mathrm{~cm}^{-1}$ (MWD) (Leopold et al., 2011). Partial overlapping of the absorption band is noticed for carboxyl $(\mathrm{C}=0)$ and amide $(\mathrm{N}-\mathrm{H})$, at peak value $1680-1630 \mathrm{~cm}^{-1}$ and $1640-1620 \mathrm{~cm}^{-1}$ respectively. C-O bond shows stretching vibration at $2123-2126 \mathrm{~cm}^{-1}$ because of the non-ionic carboxylic group or their ester acid $\left(-\mathrm{COOH},-\mathrm{COOCH}_{3}\right)(\mathbf{R a m b l a}$ et al., 1998). Symmetric stretching frequency of $-\mathrm{CH}_{2}$ lie at the peak value of $2931 \mathrm{~cm}^{-1}$ (HAD) whereas either of symmetric or asymmetric C-H stretching frequency of aliphatic acids is represented by a peak at $2932 \mathrm{~cm}^{-1}$ (SD, HAD, MWD, and FD). Absorption frequency of hydroxylation lies in the region of 3700 to $3000 \mathrm{~cm}^{-1}$. It has been observed that stretching frequency of $-\mathrm{OH}$ mostly retains at $3377 \mathrm{~cm}^{-1}$ (SD) (Ajila et al., 2010). Amide (N-H) stretching frequency is observed in the range of $3500-3000 \mathrm{~cm}^{-1}$. From the study, it can be noted that this stretching frequency is noticed for all products dried under four different methods (SD, HAD, MWD, and FD). Stretching frequency of hydroxyl (O-H) group in alcohols, phenols, carboxylic acid available in pectin, lignin, cellulose (Adina et al., 2010) shows a broad peak at 3557 (MWD) and $3353 \mathrm{~cm}^{-1}$ (HAD). This can be explained by the phenomena of having intra and intermolecular $-\mathrm{H}$ bonds of such compounds.

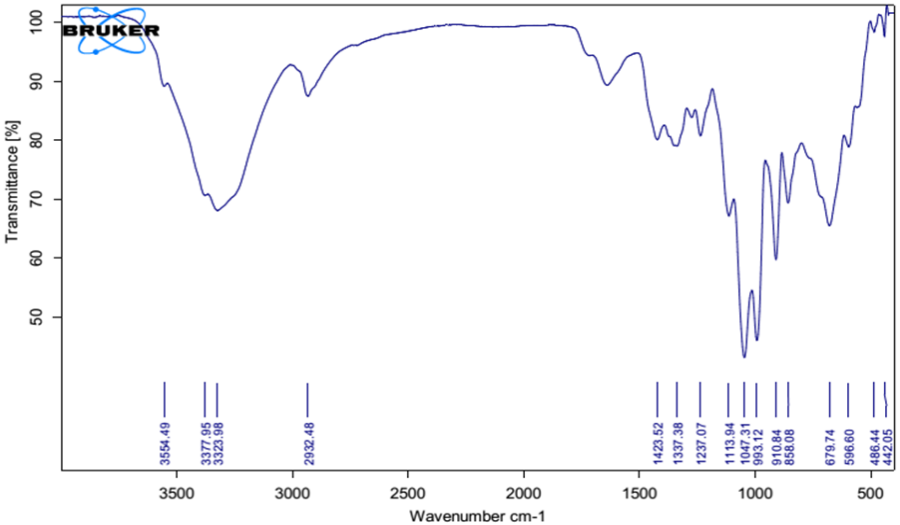

Figure 2 FTIR spectra of Freeze dried mango leather

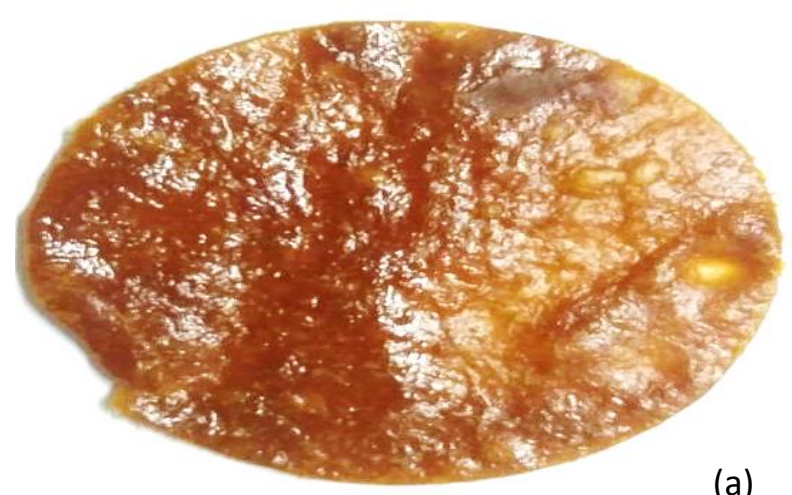

(a)

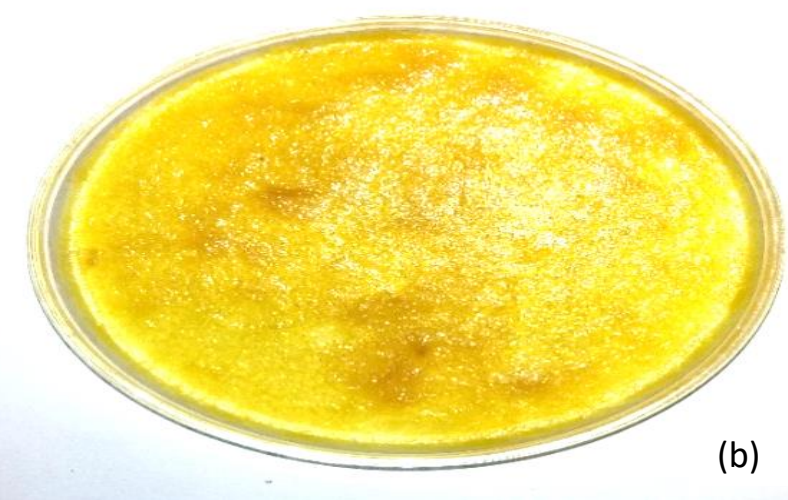

(b)

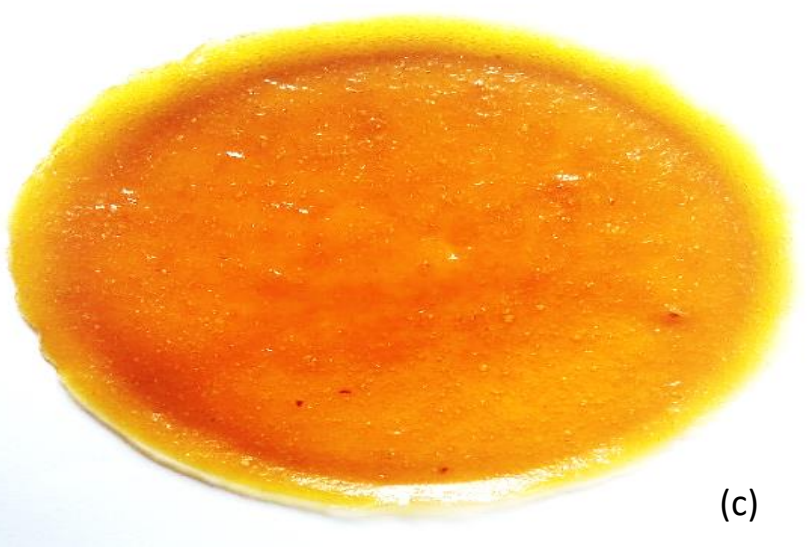




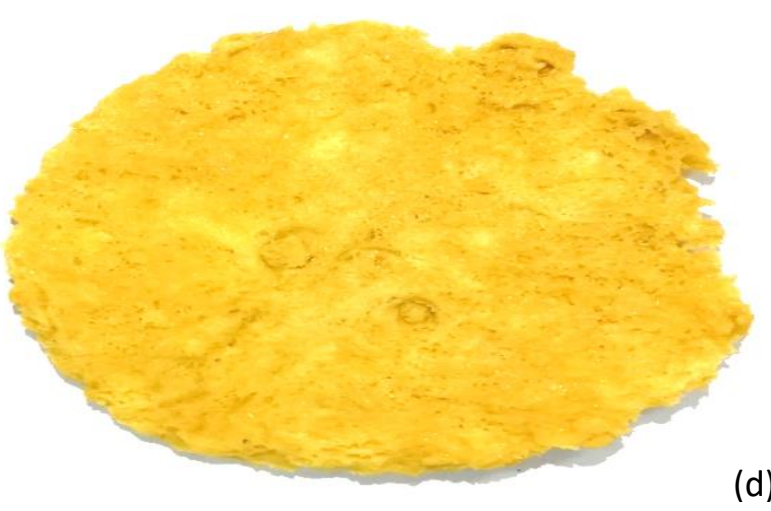

Fig. 3. Different types of Mango leather - (a) Hot Air Oven dried mango leather. (b) Microwave dried mango leather; (c). Freeze dried mango leather; (d) Sun dried mango leather.

\section{SENSORY EVALUATION}

The panelists and panel performance was evaluated towards the sample attributes. Panelists significantly perceive the variance within samples (Fig. 3a, $3 \mathrm{~b}, 3 \mathrm{c}, 3 \mathrm{~d}$ ), with respect to orange-yellow colour, rigidity, surface finish, chewiness, and aftertaste. The panelists attained a low p-value as well as low MSE values for all the sensory attributes, by the development of constellation adjacent the lower-left portion of the plot, inferring the samples are categorically dissimilar from each other.

(d)

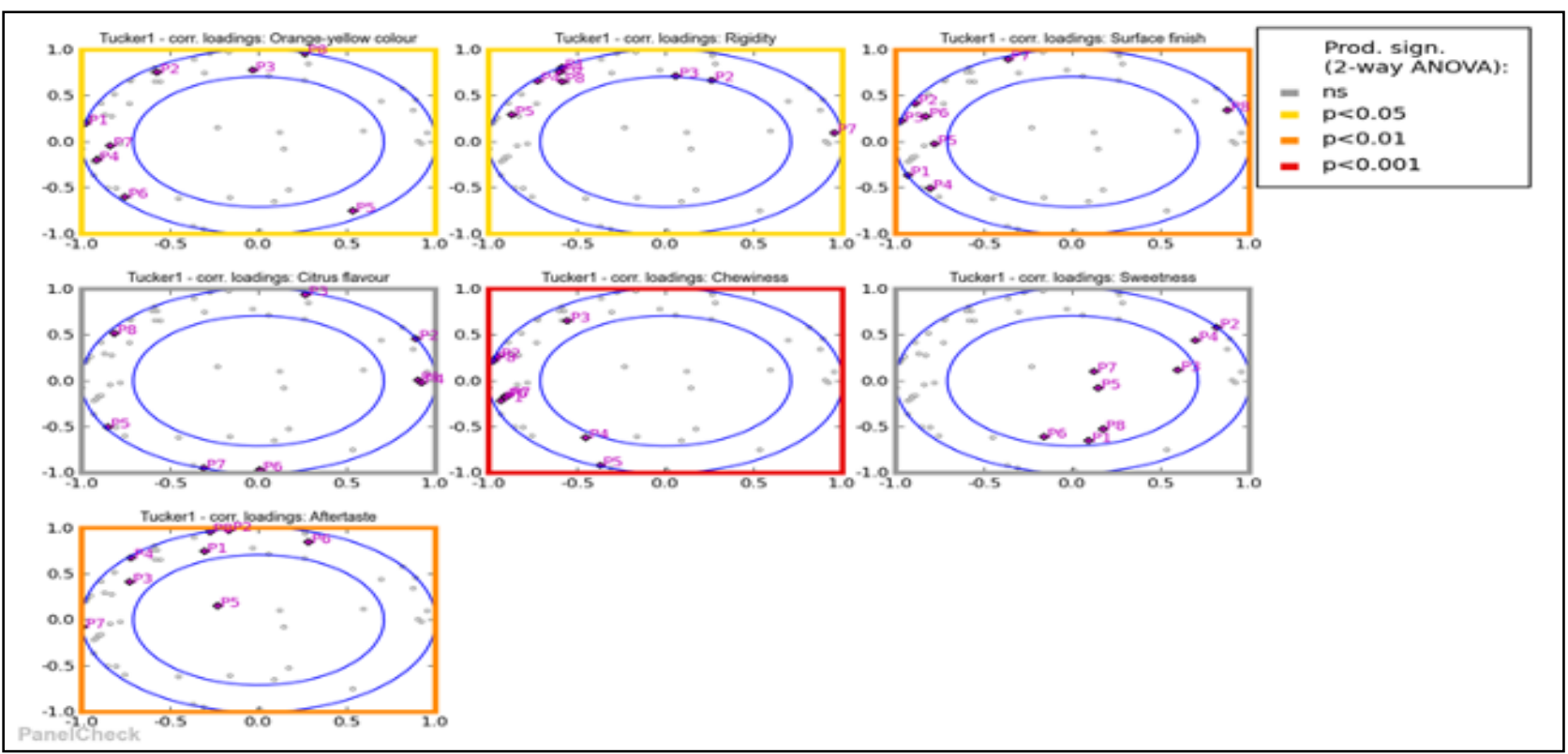

Figure 4 Tucker 1 plot for each sensory attribute. The borders exterior the outer eclipse represents the statistical significance in different p-value

The multivariate approach of analysis produces the Tucker-1 plot (Fig.4.), where specific incongruity was observed for statistically significant $(\mathrm{p}<0.5)$ attribute aftertaste (P5) and insignificant ( $>$ > 0.5) attribute sweetness (P1, P3, P5, P6, P7, and P8). For all the other attributes no such discrepancies have been observed. Regardless of these disagreements, most of the panelists were accommodated in the outer eclipse, recommending $100 \%$ of explained variance for each attribute. It was also found that the explained variances accommodated themselves within the first two principal components (PC), by predicting the pronounced systematic variation of analyzed data set proposing the panel is well-trained and static Instead of a panel, samples are considered during consensus analysis of the data set. The standardized PCA Bi-plot (Fig.5) describe that mutually axis 1 and 2 showed a very high correlation (70.6\% and $26.3 \%$ ) among all sensory attributes. The attributes like citrus flavour and sweetness reside on the positive side of the PC1, while orange-yellow colour, chewiness, surface finish, rigidity, and aftertaste belong to the negative side of PC1. On a similar fashion, sweetness, rigidity, and aftertaste were observed at the positive coordinate of PC 2, though four other attributes namely orange-yellow colour, surface finish, citrus flavour, and chewiness observed at the negative side of PC 2 .

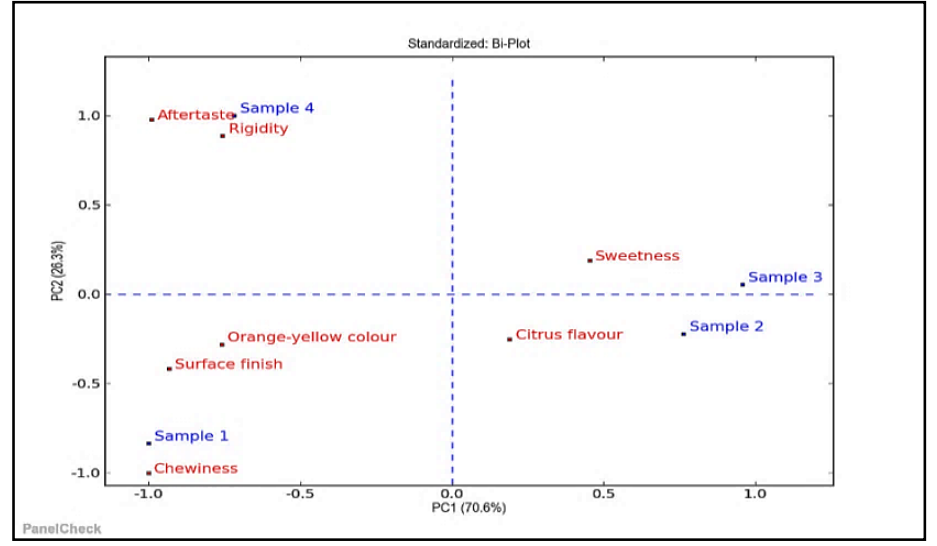

Figure 5 PCA Bi-plot for Sun dried (Sample 1), Hot air dried (Sample 2), Microwave dried (Sample 3) and Freeze dried (Sample 4) mango leather.

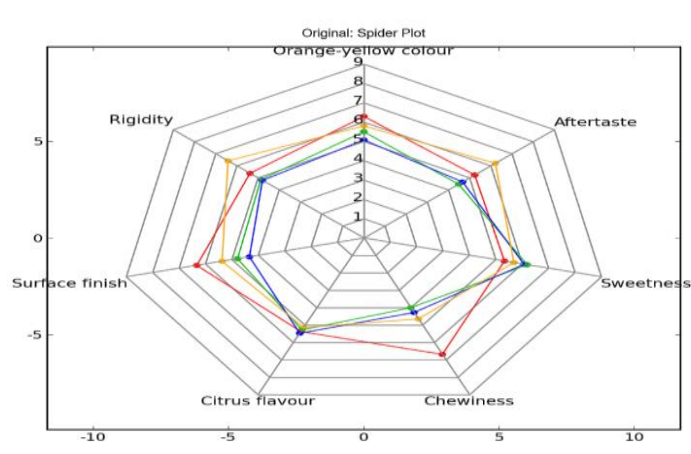

\begin{tabular}{|l|}
\hline - Sample 1 \\
= Sample 2 \\
- Sample 3 \\
- Sample 4 \\
\hline
\end{tabular}

Figure 6 Spider for Sun dried (Sample 1), Hot air dried (Sample 2), Microwave dried (Sample 3) and Freeze dried (Sample 4) mango leatherThe SD (sample 1) 
was more correlated with orange-yellow colour, surface finish and chewiness, HAD (sample 2) and MWD (sample 3) were found to be more correlated with citrus flavour and sweetness respectively. FD (sample 4) was found to be correlated with sensory attributes like rigidity and aftertaste. SD was appeared to be preeminent regarding orange-yellow colour, surface finish, and chewiness, whereas HAD and MWD found to be superlative with respect to sweetness and citrus flavour respectively, while the attributes like rigidity and aftertaste found to be superior for FD. Spider plot (Fig. 6) showed the overall representation of the sensory attributes which was in accordance with information acquired Fig. 5 Surface finish, orange yellow colour, and chewiness were the attributes where SD (sample 1) showed its superiority. While FD (sample 4) showed the maximum score in terms of rigidity and aftertaste. MWD (sample 3) showed the highes citrus flavour development. HAD (sample 2) was scored maximum in terms of sweetness.

\section{CONCLUSION}

Thin-layer drying models were studied for mango leather and Midilli model was fitted best with the maximum value for $\mathrm{R}^{2}$ of $0.999479,0.999567,0.999998$, 0.99877 along with minimum RMSE and SSE value of $0.006283,0.005867$, $0.000425,0.010534$ and $0.00122,0.0006539,0.000003,0.00233$ for sun, hot air microwave and freeze drying respectively. The effective diffusivity was found maximum for MWD $\left(2363 \times 10^{-7} \mathrm{~m}^{2} / \mathrm{s}\right)$ followed by HAD $\left(193.7 \times 10^{-7} \mathrm{~m}^{2} / \mathrm{s}\right)$, FD $\left(44.63 \times 10^{-7} \mathrm{~m}^{2} / \mathrm{s}\right)$ and sun drying $\left(26.37 \times 10^{-7} \mathrm{~m}^{2} / \mathrm{s}\right)$. SD was the lengthiest $(32$ hours) process, while MWD being the shortest (96 minutes) method for mango leather production. The FTIR analysis implied that different drying methods insignificantly affect the carbohydrate composition. SD was found better with respect to its distinguished orange-yellow appearance, smoothness of the surface, and chewability, however, HAD and MWD were exceptional with compared to sweetness and characteristics citrus flavour of mango leather respectively, whereas, in terms of rigidity and aftertaste FD was preferred most.

\section{Compliance with ethical standards}

Conflict of interest: Authors declare no conflict of interest.

\section{REFERENCES}

Acar, B., Sadikoglu, H., Doymaz, I. (2014). Freeze-drying kinetics and diffusion modelling of saffron (Crocus sativus L.), Journal of Food Processing and Preservation, 39 (2). https://dx.doi.org/10.1111/jfpp.12214

Adina, C., Fetea, F., Taoutaou, A., Socaciu, C. (2010). Application of FTIR spectroscopy for a rapid determination of some hydrolytic enzymes activity on sea buckthorn substrate, Romanian Biotechnological Letters, 15(6), 5738-5744.

Ajila, C. M., Rao, J. M. L., Rao, U. P. (2010). Characterization of bioactive compounds from raw and ripe Mangifera indica L. peel extracts. Food and chemical toxicology, 48(12), 3406-3411. https://dx.doi.org/10.1016/j.fct.2010.09.012

Alara, O. R., Nour, A., Mudalip, S. K. A., Olalere, O. A. (2018). Mathematical Modeling of Thin Layer Drying using Open Sun and Shade of Vernonia amygdalina Leaves, Agriculture and Natural Resources, 52. https://dx.doi.org/10.1016/j.anres.2018.05.013

Arslan, D., Özcan, M. (2010). Study the effect of sun, oven and microwave drying on quality of onion slices. LWT - Food Science and Technology, 43(7), 1121-1127. https://dx.doi.org/10.1016/j.lwt.2010.02.019

Bualuang, O., Onwude, D. I., Pracha, K. (2017). Microwave drying of germinated corn and its effect on phytochemical properties. Journal of the science of food and agriculture, 97 (9). https://dx.doi.org/10.1002/jsfa.8140

Demiray, E., Seker, A., Tulek, Y. (2017). Drying kinetics of onion (Allium cepa L.) slices with convective and microwave drying, Heat and Mass Transfer, 53(5), 1-11. https://dx.doi.org/10.1007/s00231-016-1943-X

Dinani, S. T., Hamdami, N., Shahedi, M., Havet, M. (2014). Mathematical modelling of hot air/electro hydrodynamic (EHD) drying kinetics of mushroom slices, Energy Conversion and Management, 86, 70-80. https://dx.doi.org/10.1016/j.enconman.2014.05.010

Dissa, A. O., Bathiebo, J., Kam, S., Savadogo, P., Desmorieux, H., Koulidiati, J. (2009). Modelling and experimental validation of thin layer indirect solar drying of mango slices. Renewable Energy, 34, 1000-1008. https://dx.doi.org/10.1016/j.renene.2008.08.006
Dissa, A. O., Desmorieux, H., Bathiebo, J., Koulidiati, J. (2008). Convective drying characteristics of Amelie Mango (Mangifera Indica L. cv. 'Amelie') with correction for shrinkage, Journal of Food Engineering, 88(4), 429-437. https://dx.doi.org/10.1016/j.jfoodeng.2008.03.008

Duarte, I. F., Barros, A., Delgadillo, I., Almeida, C., Gil, A. M. (2002). Application of FTIR Spectroscopy for the Quantification of Sugars in Mango Juice as a Function of Ripening, Journal of Agricultural and Food Chemistry, 50 (11), 3104-3111. https://dx.doi.org/10.1021/jf011575y

Erwanto, Y., Muttaqien, A., Sugiyono, Sismindari S., Rohman, A. (2016). Use of Fourier Transform Infrared (FTIR) Spectroscopy and Chemometrics for Analysis of Lard Adulteration in "Rambak" Crackers, International Journal of Food $\begin{array}{lll}\text { Properties, } & 19 & \text { (12), 2718-2725 }\end{array}$ https://dx.doi.org/10.1080/10942912.2016.1143839

Fernando J. A. K. M., Amarasinghe, A. D. U. S. (2016). Drying kinetics and mathematical modeling of hot air drying of coconut coir pith, Springer Plus, 5 (1), 807. https://dx.doi.org/10.1186/s40064-016-2387-y

Goyal, R. K., KIngsly, A., Ramarathinam, M. (2006). Thin-layer drying kinetics of raw mango slices, Biosystems Engineering, 95(1), 43-49. https://dx.doi.org/10.1016/j.biosystemseng.2006.05.001

Henderson, S. M., Pabis, S. (1961). Grain drying theory II. Temperature effects on drying coefficients, Journal of Agricultural Engineering Research, 44 (2), 1111-1122

Isleroglu, H. (2019). Freeze drying and moisture adsorption kinetics of kefir powder, Italian Journal of Food Science, 31 (3).1120-1770 https://dx.doi.org/10.14674/IJFS-1382

Izli, N., Izli, G., Taskin, O. (2016). Drying kinetics, colour, total phenolic content and antioxidant capacity properties of kiwi dried by different methods, Journal of Food Measurement and Characterization, 11(1). https://dx.doi.org/10.1007/s11694-016-9372-6

Jha, S. N., Gunasekaran, S. (2010). Authentication of sweetness of mango juice using Fourier transform infrared-attenuated total reflection spectroscopy, Journal of Food Engineering, 101 (3), 337-342.

Kumar, P. S., Sagar, V. R. (2014). Drying kinetics and physico-chemical characteristics of Osmo- dehydrated Mango, Guava and Aonla under different drying conditions. Journal of Food Science and Technology, 51(8), 1540-1546. https://dx.doi.org/10.1007/s13197-012-0658-3

Leizi, J., Daming, D., Han, P., Zhao, X., Xiaofan, D. (2017). Identification of Mango Maturity Level by the Analysis of Volatiles Based on Long Optical-Path FTIR Spectroscopy and Molecular Sieve, Analytical methods, 9(16) https://dx.doi.org/10.1039/C7AY00149E.

Leopold, L., Leopold, N., Diehl, H.-A., Socaciu, C. (2011). Quantification of carbohydrates in fruit juices using FTIR spectroscopy and multivariate analysis, Spectroscopy, 26 (2), 93-104.

Lestringant, P., Delarue, J., Heymann, H. (2019). 2010-2015 How have conventional descriptive analysis methods really been used - A systematic review of publications, Food Quality and Preference, 71, 1-7. https://dx.doi.org/10.1016/j.foodqual.2018.05.011.

Lewis, W. K. (1921). The rate of drying of solid materials. Indian Chemical Engineer, 13 (5), 427-443. https://dx.doi.org/10.1021/ie50137a021

Maskan A, Kaya S, Maskan M (2002) Hot air and sun drying of grape leather (pestil). Journal of Food Engineering, $54 \quad$ (1), 81-88. https://dx.doi.org/10.1016/S0260-8774(01)00188-1

Midilli, A., Kucuk, H., Yapar, Z. A. (2002). A new model for single layer drying, Drying Technology, 20 (7), 1503-1513. https://dx.doi.org/10.1081/DRT120005864

Ojha, P., Adhikari, R., Karki, R., Mishra, A., Subedi, U., \& Karki, T. B. (2018). Malting and fermentation effects on antinutritional components and functional characteristics of sorghum flour. Food Science \& Nutrition, 6(1), 47 53.https://doi.org/10.1002/fsn3.525

Olale, K., Waudo, W., Mohammed, S. A., Sila, A., Shepherd, K. D. (2017) Application of DRIFT-FTIR spectroscopy for quantitative prediction of simple sugars in two local and two Floridian mango (Mangifera indica L.) cultivars in Kenya. Journal of Analytical Science and Technology, 8 (21). https://dx.doi.org/10.1186/s40543-017-0130-0

Onwude, D. I., Hashim, N., Janius, R. B., Nawi, N. M., Abdan , K. (2016) Modeling the thin-layer drying of fruits and vegetables: A review, Comprehensive Reviews in Food Science and Food Safety , 15(3), 599-618, https://dx.doi.org/10.1111/1541-4337.12196 
Page, G. (1949). Factors influencing the maximum rates of air-drying shelled corn in thin layers, M.S. Thesis. Lafayette, Purdue University West Lafayette, Indiana.

Philip, S. O., Dairo, O. U., Sanni, L. O. , Odunewu, A. V., Fafiolu, B. O. (2007). Thin layer drying process of some leafy vegetables under open sun, Food Science and Technology International, $13 \quad$ (1), 35-40. https://dx.doi.org/10.1177/1082013207075953

Rahman, M. S., Perera, C. O., Thebaud, C. (1998). Desorption isotherm and heat pump drying kinetics of peas. Food Research International, 30 (7), 485-491.

Rajkumar, P., Kulanthaisami, S., Raghavan, V. G. S., Gariépy, Y., Orsat, V. (2007). Drying kinetics of toato slices in vacuum assisted solar and open sun drying methods, Drying Technology, 25(7), 1349-1357. https://dx.doi.org/10.1080/07373930701438931

Rambla, F. J., Garrigues, S., Ferrer, N., Guardia, M. d. 1. (1998). Simple partial least squares-attenuated total reflectance Fourier transform infrared spectrometric method for the determination of sugars in fruit juices and soft drinks using aqueous standards. Analyst, 277-281. https://dx.doi.org/10.1039/a704573e

Salim, N. S. M., Gariepy, Y., Raghavan, V. G .S. (2017). Hot air drying and microwave-assisted hot air drying of broccoli stalk, Journal of Food Processing and Preservation. https://dx.doi.org/10.1111/jfpp.12905

Sarkar T, Nayak P, Chakraborty R (2020) Storage study of mango leather in sustainable packaging condition. Materials Today: Proceedings, 22 (4), 20012007, https://doi.org/10.1016/j.matpr.2020.03.177.

Sarkar, T., Salauddin, M., Hazra, S.K., Chakraborty, R. (2020). Effect of cutting edge drying technology on the physicochemical and bioactive components of mango (Langra variety) leather. Journal of Agriculture and Food Research.

Sarkar, T., Salauddin, M., Hazra, S.K., Chakraborty, R. (2020). The impact of raw and differently dried pineapple (Ananas comosus) fortification on the vitamins, organic acid and carotene profile of dairy rasgulla (sweetened cheese ball), Heliyon, 6(10). https://doi.org/10.1016/j.heliyon.2020.e05233.

Sarkar, T., Salauddin, M., Hazra, S.K., Chakraborty, R. (2020). Artificial neural network modelling approach of drying kinetics evolution for hot air oven, microwave, microwave convective and freeze dried pineapple. SN Applied Sciences. https://doi.org/10.1007/s42452-020-03455-x.

Sarkar, T., Salauddin, M., Hazra, S.K., Chakraborty, R. (2020).Comparative study of predictability of response surface methodology (RSM) and artificial neural network-particle swarm optimization (ANN-PSO) for total colour difference of pineapple fortified rasgulla processing. International Journal of Intelligent Networks 1. 17-31. https://dx.doi.org/10.1016/j.ijin.2020.06.001.

Sarkar, T., Chakraborty, R. (2018). Formulation, Physicochemical Analysis, Sustainable Packaging-Storage Provision, Environment Friendly Drying Techniques and Energy Consumption Characteristics of Mango Leather Production: A Review, Asian Journal of Water, Environment and Pollution, 15 (3), 79-92. https://dx.doi.org/10.3233/AJW-180046.

Sufer, O., Sezer, S., Demir, H. G. (2017). Thin layer mathematical modelling of convective, vacuum and microwave, Journal of food processing and preservation. https://dx.doi.org/10.1111/jfpp.13239

Wang, G. Y., Singh, R. P. (1978). A single thin layer drying equation for drying rough rice, Materials Science.

Wang, J., Wang, J. S., Yu, Y. (2007). Microwave drying characteristics and dried quality of pumpkin, International Journal of Food Science \& Technology, 42 (2), 148 - 156. https://dx.doi.org/10.1111/j.1365-2621.2006.01170.x

White, G. M., Ross, I. J., Ponelert. (1981). Fully exposed drying of popcorn, Transactions of the American Society of Agricultural Engineers, 24,466-468. https://dx.doi.org/10.13031/2013.34276

Yaldı, O., Ertekin, C. (2001). Thin layer solar drying of some vegetables. Drying Technology, 19 (3-4), 583-596. https://dx.doi.org/10.1081/DRT100103936

Zarein, M., Samadi, S. H., Ghobadian, B. (2013). Investigation of microwave dryer effect on energy efficiency during drying of apple slices, Journal of the Saudi Society of Agricultural Sciences, 14 (1), 41-47. https://dx.doi.org/10.1016/j.jssas.2013.06.002 